\title{
Defective Development of the Thymus and Immunological Abnormalities in the Neurological Mouse Mutation "Staggerer"
}

\author{
Ekkhart Trenkner* and Michael K. Hoffmann $\dagger$ \\ *Department of Pharmacology, New York University Medical Center, New York, New York 10016, and \\ † Memorial Sloan-Kettering Cancer Center, New York, New York 10021
}

\begin{abstract}
The autosomal recessive mouse mutation "staggerer" (sg/sg), located on chromosome 9 , has been recognized as a neurological mutant because of movement abnormalities and defective cerebellar development. We show here that the $s g / s g$ mutation not only affects the development of the cerebellum, but also causes developmental and regulatory changes of the immune system: We observed, on gross inspection, a marked delay in the development of $s g / s g$ thymus, generally enlarged lymph nodes, and undersized spleens. When immunized with SRBC, the sg/sg mouse generated, in normal proportions, helper T-cells in vivo and antibody-forming B-cells in vitro; however, a delay in terminating the response and a deficiency in generating suppressor cells was noted. This suggests the existence of a defect in regulatory feedback mechanisms. The marked delay in the growth of the thymus gland was associated with the prolonged existence of cell-surface carbohydrate patterns characteristic of immature thymocytes. The prolonged expression of embryonal cell-surface phenotypes was observed on the surface of cerebellum and thymus (and, to some extent, spleen) but not in cells from other organs.
\end{abstract}

Inherited diseases are frequently characterized by patterns of multiple disorders. These patterns suggest developmental relationships between affected functions (or organs) and raise the question of whether a given mutation affects the development of different systems independently or if a defect in one system causes dysfunction in others. In this report we examine the development of the thymus and immune dysfunctions in the "staggerer" ( $(\mathrm{sg} / \mathrm{sg}$ ) mouse. The $s g / s g$ mutation occurred spontaneously at the Jackson Laboratories (Sidman et al., 1962). It is described as autosomal recessive; the gene has been mapped on chromosome 9, 12 centimorgans from the thy-1 locus (Roderick and Davisson, 1982). The abnormal motions (ataxic gait) of $s g / s g$ mice are attributed to defective development of the cerebellum (Landis and Sidman, 1978; Sidman, 1968).

Results reported here indicate that the $\mathrm{sg} / \mathrm{sg}$ mutation does not affect the development of the cerebellum exclusively; it also affects the development of the thymus, resulting in distinct immunological abnormalities.

\section{Materials and Methods}

Animals

Staggerer (sg/sg) mutant mice with a C57/BL background (C57BL, dse/ $\mathrm{sg}^{++}$) and their healthy littermates (dsc/dsc) wcre bred in our mousc

\footnotetext{
Received Aug. 26, 1985; revised Nov. 27, 1985; accepted Dec. 18, 1985.

We would like to thank Dr. W. Wille for the initial determinations of neuraminidase activity, and Dr. S. Green for discussions and a critical reading of the manuscript. This work was supported by NSF Grant 7922673 (to E.T.) and NIH Grant CA 17673 (to M.K.H.).

Correspondence should be addressed to E. Trenkner, Department of Pharmacology, NYU Medical Center, 550 First Avenue, New York, NY 10016.

Copyright (C) 1986 Society for Neuroscience $0270-6474 / 86 / 061733-05 \$ 02.00 / 0$
}

colony at NYU Medical Center. Healthy littermates, homozygous normal with respect to the staggerer mutation, were identified by their gray coat color (d/d) and short ears (se/se) and will be referred to in the text as $+/+$. Homozygous $s g / s g$ mice die at weaning under standard breeding conditions, but about $90 \%$ survive more than 12 months when caged with foster mothers and fed daily with Charles River shipping food (Charles River, Wilmington, MA). Balb/c nude $(\mathrm{Nu} / \mathrm{Nu})$ mice were obtained from the National Cancer Institute.

\section{Characterization of cell-surface carbohydrate pattern}

Cell-surface carbohydrates were identified in $\mathrm{sg} / \mathrm{sg}$ and $+/+$ thymocytes and splenocytes by using the antibodies to bacterial polysaccharide employed to determine carbohydrate pattern on cerebellar cell surfaces (Trenkner, 1979; Trenkner and Sarkar, 1977). Thymocytes and splenocytes were prepared as described (Mishell and Dutton, 1967), washed once in balanced salt solution (BSS), and incubated with antibody for $1 \mathrm{hr}$ on ice, washed $3 \times$ in BSS, incubated for $20 \mathrm{~min}$ at $4^{\circ} \mathrm{C}$ in the presence of FITC-labeled goat anti-rabbit Ig (1:80), washed $3 \times$ with BSS at $4^{\circ} \mathrm{C}$, and analyzed for immunofluorescence.

\section{Assay for particulate neuraminidase activity}

The neuraminidase-containing particulate fraction from thymus $(+/+$ and $s g / s g$ ) was prepared following the procedure of Carubelli and Tulsiani (1971). All operations were conducted on ice. Homogenates were prepared in $0.25 \mathrm{~m}$ sucrose $/ 1 \mathrm{~mm}$ EDTA with a glass homogenizer fitted with a mechanically driven Teflon pestle, followed by centrifugation for $1 \mathrm{hr}$ at 105,000 $\times \mathrm{g}$. The pellet was washed twice and resuspended in water [protein concentration, $2.5-7.0 \mathrm{mg} / \mathrm{ml}$ as determined by the method of Lowry et al. (1951)]. Assay for neuraminidase was carried out as described by Bharanandan et al. (1975) with neuraminosyl $\alpha 2 \rightarrow 3,6$ lactit ${ }^{3} \mathrm{H}$-ol (New England Nuclear) as substrate.

\section{Cell cultures}

Suspensions of spleen cells were prepared and immunized in vitro according to Mishell and Dutton (1967), except that 2-mecaptoethanol was added to the culture medium $\left(5 \times 10^{-5} \mathrm{M}\right)$. The number of plaqueforming cells (PFC) was determined in a modified Jerne plaque assay (Jerne et al., 1963).

\section{Suppressor T-cell activity}

The ability of $s g / s g$ and $+/+$ mice to generate suppressor T-cells when stimulated with $\mathrm{H}-2 \mathrm{~d}$ alloantigen was tested in vitro by adding to their spleen cells $\left(\mathrm{H}-2^{\mathrm{b}}\right)$ those from $\mathrm{Balb} / \mathrm{c} \mathrm{Nu} / \mathrm{Nu}$ mice $\left(\mathrm{H}-2^{\mathrm{d}}\right)$. Cell mixtures were immunized with SRBC in the presence of lymphokine interleukin 1 (IL-1) (Hoffmann, 1980) and TRF (Hoffmann and Watson, 1979) in concentrations that permitted effective antibody production by antigenreactive B-lymphocytes.

\section{Results}

Macroscopic abnormalities in the growth of thymus, lymph nodes, and spleen

Abnormalities in the immune system of the $\mathrm{sg} / \mathrm{sg}$ mutant mouse are noticeable by gross observation. We found a marked delay in the growth of the thymus gland in $s g / s g$ compared with that 


\section{THYMUS}

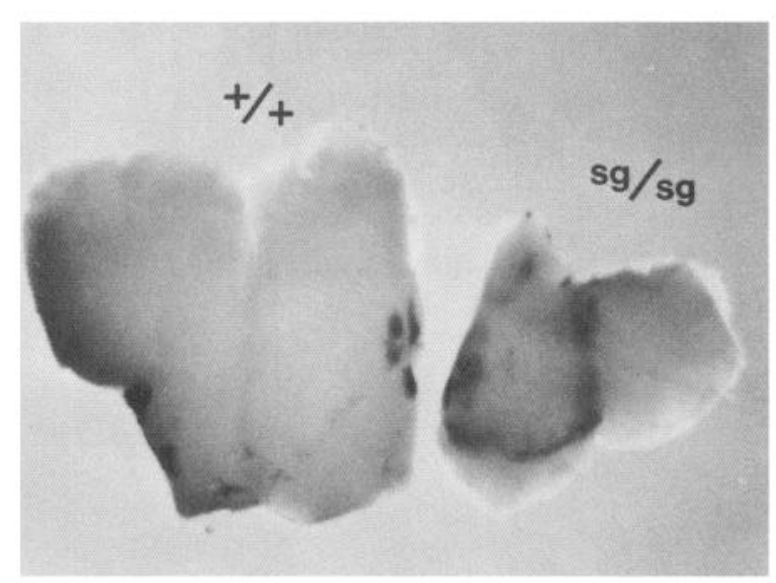

SPLEEN

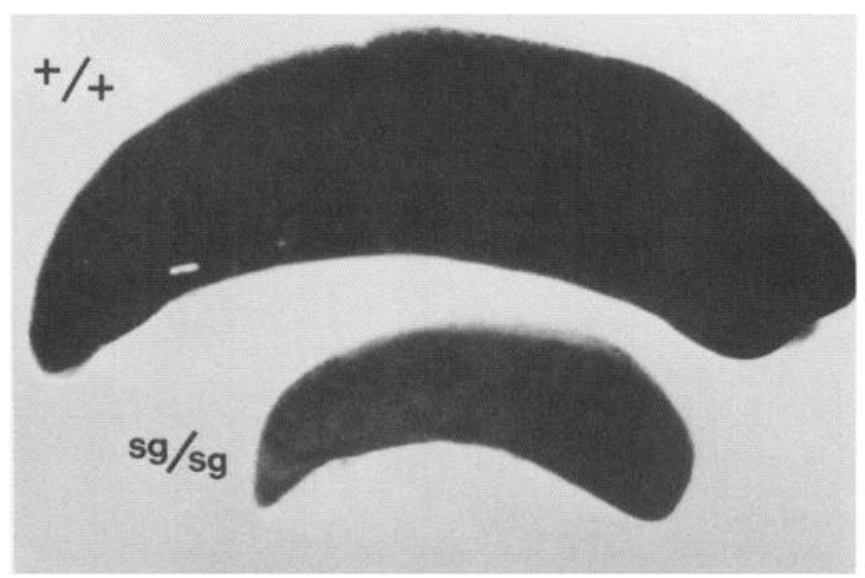

Figure 1. Thymus and spleen of $15-\mathrm{d}$-old $+/+$ and $s g / s g$ mice.

in littermates $(+/+)$ (Fig. 1, top). The difference in thymus weight between both experimental groups disappeared within 3-4 months (Fig. 2) because of the involution of thymus in $+/+$ mice and a delayed onset of growth of the thymus in $\mathrm{sg} / \mathrm{sg}$ mice. While lymph nodes were (often substantially) swollen in most $s g / s g$ mice, their spleens were comparatively small (Fig. 1, lower), containing usually less than half the number of cells of $+/+$ spleens.

\section{Cell-surface carbohydrate metabolism}

Both cerebellum and thymus of $s g / s g$ are delayed in the developmentally regulated expression of cell-surface glycoproteins and glycolipids (Trenkner, 1979; Trenkner and Sakar, 1977; Wille and Trenkner, 1980). In normal animals, $\alpha 2 \rightarrow 8$ polysialic acid moieties characteristic of embryonic cerebellar cells disappear within the first $3 \mathrm{~d}$ of life and are replaced by $\alpha 2 \rightarrow 6$ polysialic acid residues (Trenkner and Sarkar, 1977). In $s g / s g$, by contrast, the embryonic form is maintained on cerebellar cells postnatally (Edelman and Chuong, 1982; Hatten and Messer, 1978; Trenkner, 1979). We have now found, using immunochemical techniques, similar developmental abnormalities on $s g / s g$ thymocytes and splenocytes (Table 1). Eighty-two percent of adult $\mathrm{sg} / \mathrm{sg}$ thymocytes (4-5 weeks) carried the embryonic surface antigen compared to $32 \%$ in $+/+$. The adult form of neuraminic acid was expressed on $62 \%$ of $+/+$ thy-

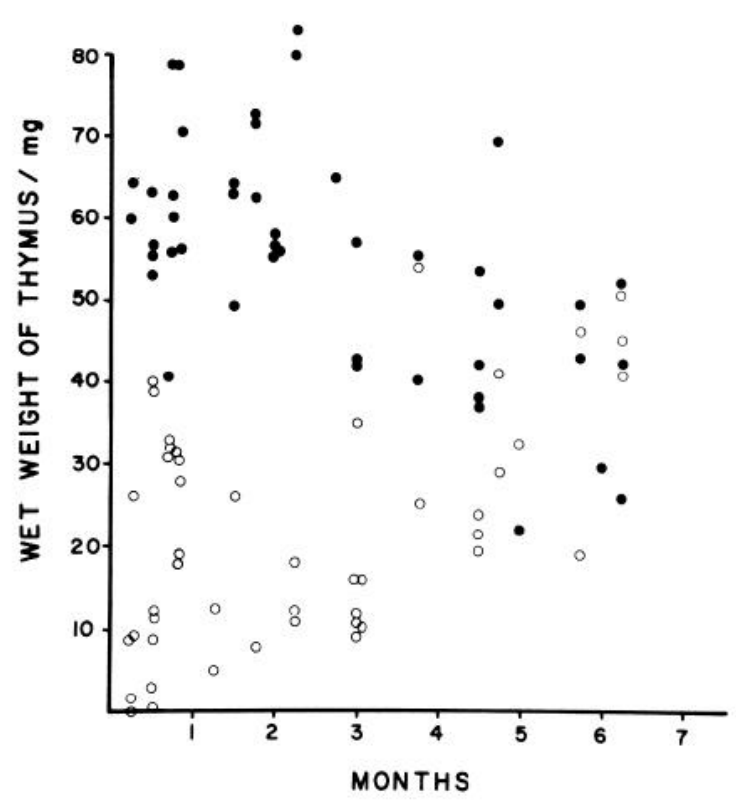

Figure 2. The wet weights of $+/+(\bullet)$ and $s g / s g(0)$ thymus glands were determined at various times after birth. Each spot represents the weight of one thymus.

mocytes and $15 \%$ of $s g / s g$ thymocytes. A similar pattern was observed with splenocytes, which is somewhat surprising because these changes cannot be entirely attributed to the influx of T-cells from the thymus. Non-T-cells, like T-cells, seem to retain embryonic surface qualities for a prolonged period of time.

Particulate neuraminidase (sialidase EC 3.2.1.18) has been found to be developmentally regulated with two peaks of activity at P3 and P21. The P3 peak of neuraminidase activity does not occur in the developing cerebellum of $s g / s g$ (Wille and Trenkner, 1980). This developmental abnormality has not been found in $s g / s g$ cerebrum and liver. In view of the thymus abnormalities related to the $s g / s g$ mutation, we extended our studies to measure developmentally controlled neuraminidase activity in $\mathrm{sg} /$ $s g$ thymocytes. We found that in this parameter, as well, the thymus exhibited the developmental characteristics of the cerebellum: It did not produce the early peak of neuraminidase activity. The second peak (P21) was found to be substantially increased (Fig. 3). The neuraminidase assay was performed for $s g / s g$ on $\mathrm{P} 4$; it is at this time that the $s g / s g$ mutation becomes recognizable. Neuraminidase activity of both $+/+$ and $s g / s g$ spleens was less than $10 \%$ of that found in thymus and at the borderline of detectability (not shown).

\section{Humoral primary immune response}

The ability of $\mathrm{sg} / \mathrm{sg}$ mice to mount a humoral immune response was tested in vitro using the Mishell-Dutton culture system (1967). $S g / s g$ and $+/+$ spleen cell suspensions were immunized with SRBC, and antibody production was determined on days $4,5,6$, and 7 (Table 2). Both groups responded similarly in magnitude; however, the response declined more sharply in cultures of $+/+$ spleen cells than in cultures of $s g / s g$ spleen cells, suggesting abnormalities in mechanisms which terminate the production of antibody.

\section{T-helper function}

Abnormalities in feedback control were further suggested by subsequent experiments in which we tested the response of T-cells to SRBC. Mice were immunized with SRBC, and the ability of responding helper T-cells to cooperate with B-lympho- 


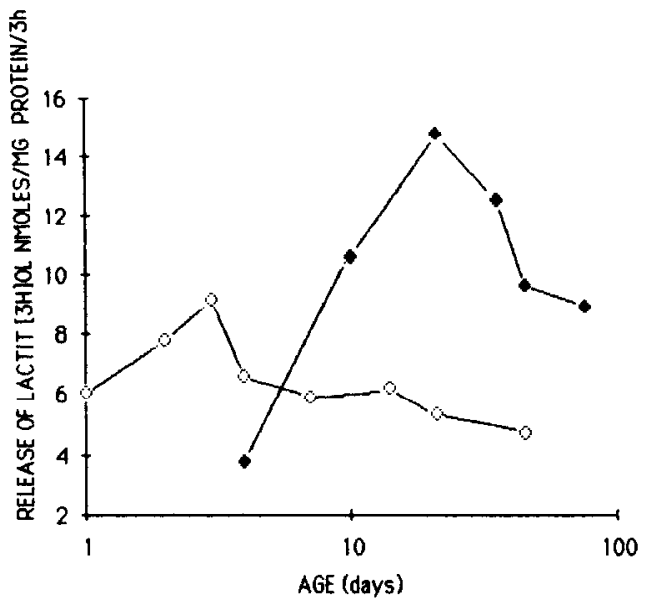

Figure 3. Neuraminidase activity in the developing thymus of $+1+$ and $\mathrm{sg} / \mathrm{sg}$ mice. The neuraminidase-containing particulate fractions from thymus of both $+1+(\diamond)$ and $s g / s g(\diamond)$ were prepared from tissue homogenates.

cytes in antibody production was determined in vitro as described previously (Hoffmann and Kappler, 1973). Graded numbers of primed spleen cells were mixed with unprimed spleen cells to a total of $5 \times 10^{6} \mathrm{cells} / \mathrm{ml}$, and the mixed cultures were immunized with TNP-conjugated SRBC (SRBC-TNP). Cooperation of SRBC-specific helper T-cells (primed) with TNPspecific B-lymphocytes (unprimed) was assessed by determining the anti-TNP PFC response in these cultures on day 4 . The magnitude of the anti-TNP response in this setting is a direct function of the helper activity of the carrier-primed T-cells (Hoffmann and Kappler, 1977).

Carrier-primed T-cells from $s g / s g$ and $+/+$ littermates stimulated the anti-TNP response of $s g / s g$ and $+/+$ spleen cells of $+/+$ (Fig. 4). However, while helper T-cells from both sources exhibited similar helper activity, $s g / s g$ spleen cells responded to help far better than $+/+$ B-cells. The higher response of $s g /$ $s g$ cells may be attributed to a higher frequency of antigenresponsive B-cells in the $s g / s g$ spleen or to a defective regulatory feedback mechanism.

We tried to distinguish between these possibilities in determining the frequency of B-cell precursors in $+/+$ and $\mathrm{sg} / \mathrm{sg}$, using a limited dilution technique (Lefcovitz, 1972). In repeated determinations, we found the frequencies indistinguishable, ranging, for SRBC, around 1 in $10^{4}$ spleen cells. We therefore turned our attention to suppressor T-cell mechanisms.

\section{T-suppression}

As a test for the ability of $s g / \mathrm{sg}$ spleen cells to exert negative feedback control, we determined their ability to generate sup-
Table 2. In vitro antibody production by $s g / s g$ and by $+/+$ spleen cells

\begin{tabular}{|c|c|c|c|c|c|c|}
\hline & \multicolumn{6}{|c|}{ Anti-SRBC PFC/culture } \\
\hline & Exp. & & Day 3 & Day 4 & Day 5 & Day 6 \\
\hline \multirow{6}{*}{$\begin{array}{l}s g / s g \\
+/+\end{array}$} & (1) & $s g / s g$ & 525 & 630 & 480 & 50 \\
\hline & & $+1+$ & 425 & 700 & 45 & 0 \\
\hline & $(2)$ & $s g / s g$ & 625 & 980 & 500 & 185 \\
\hline & & $+/+$ & 810 & 1250 & 60 & 0 \\
\hline & (3) & $s g / s g$ & 635 & 815 & 500 & 95 \\
\hline & & $+1+$ & 750 & 1025 & 100 & 0 \\
\hline
\end{tabular}

$5 \times 10^{6}$ Spleen cells/culture were immunized with SRBC (Mishell and Dutton, 1967). PFC were determined on the day indicated from a pool of two cultures. The described experiment is one of five that showed the same effect but varied too much in magnitude to be averaged.

pressor T-cells in response to stimulation with $\mathrm{H}-2 \mathrm{~d}$ alloantigen. $S g / s g\left(\mathrm{H}-2^{\mathrm{b}}\right)$ and $+/+\left(\mathrm{H}-2^{\mathrm{b}}\right)$ spleen cells were titrated to spleen cells from Balb/c Nu/Nu $\left(\mathrm{H}-2^{\mathrm{d}}\right)$. The cultures were stimulated with IL-1 and a fraction of supernatant from concanavalin A-stimulated C57 BL/6 spleen cells (Hoffmann and Watson, 1979) containing IL-2 and TRF (Aarden et al., 1979) and were immunized with SRBC. In the presence of these lymphokines, SRBC caused $\mathrm{Nu} / \mathrm{Nu} \mathrm{B}$ cells to produce antibody against SRBC without further T-cell help. Allogenic $s g / s g$ or $+1+$ T-cells recognizing $\mathrm{H}-2^{d}$ alloantigens on $\mathrm{Nu} / \mathrm{Nu}$ spleen cells generate suppressor cells that inhibit the response of Nu/Nu B-cells to SRBC. The degree of inhibition provides a measure for the ability of a given T-cell population to generate suppressor cells. As shown in Figure $5,+1+$ spleen cells inhibit antibody formation by $\mathrm{Nu} /$ $\mathrm{Nu}$ B-cells very effectively, while $s g / \mathrm{sg}$ spleen cells either lack this ability or are much less effective.

\section{Discussion}

The $s g / s g$ mutant mouse is easily distinguished from healthy littermates by its characteristic ataxic gait (Sidman et al., 1962), which results from a cerebellar defect. In the $\mathrm{sg} / \mathrm{sg}$ cerebellum, Purkinje cells show morphological changes, e.g., a lack of tertiary branchlet spines, the site of synapse formation between parallel fibers and Purkinje cells. Granule cells degenerate postnatally after migrating into their final position (Landis and Sidman, 1978; Sidman, 1968). We have developed an in vitro test that permits identification of distinct developmental stages in cerebellar development by defining cell-surface carbohydrate patterns with antibodies to microbial carbohydrate (Trenkner, 1979; Trenkner and Sarkar, 1977). This test, applied to $\mathrm{sg} / \mathrm{sg}$ cerebellar cells, suggested a delayed cerebellar development. Cells obtained from $s g / s g$ cerebellum of postnatal animals exhibited cell-surface carbohydrate patterns characteristic of $+1+$ prenatal cerebellar cells (Trenkner, 1979).

Table 1. Cell-surface carbohydrates of $+/+$ and $s g / s g$ thymocytes and splenocytes

Reactivity with antiserum (\%) ${ }^{a}$

\begin{tabular}{|c|c|c|c|c|c|c|}
\hline \multirow[b]{2}{*}{ Antibody } & \multicolumn{2}{|c|}{ Thymocytes } & \multicolumn{2}{|c|}{ Splenocytes } & \multicolumn{2}{|c|}{ Cerebellum $^{b}$} \\
\hline & $+1+$ & $s g / s g$ & $+1+$ & $s g / s g$ & $+/+$ & $s g / s g$ \\
\hline Anti-B $B^{c}(1: 100)$ & $31 \pm 3.5$ & $82 \pm 6.3$ & $15 \pm 1.6$ & $23 \pm 2.6$ & + & +++ \\
\hline Anti-C $C^{d}(1: 200)$ & $62 \pm 4.2$ & $15 \pm 0.8$ & $79 \pm 6.8$ & $9 \pm 1.7$ & +++ & ++ \\
\hline
\end{tabular}

\footnotetext{
${ }^{a}$ Numbers represent the average of FITC-labeled cells from 4 experiments.

"The data of the cerebellum express the degree of reactivity in postnatal day 7 cerebellar cell cultures to various antibodies (see original data in Trenkner, 1979).

"Anti-Neisseria meningococcus type $\mathrm{B}=\alpha 2 \rightarrow 8$ neuraminic acid (Finne et al., 1983).

${ }^{d}$ Anti-Neisseria meningococcus type $\mathrm{C}=\alpha 2 \rightarrow 6$ heuraminic acid (Liu et al., 1971).
} 


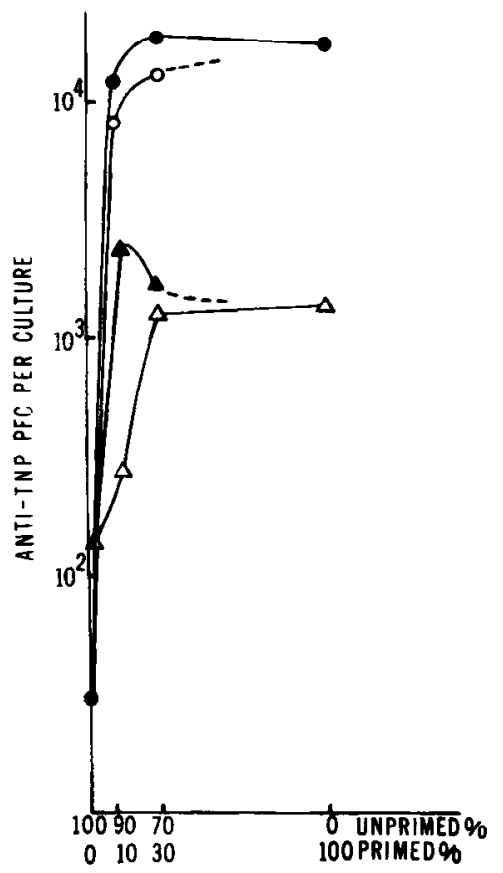

Figure 4. Cooperation of carrier-primed $s g / s g$ or $+/+$ helper T-cells with $s g / s g$ or $+/+$ B-lymphocytes. Carrier (SRBC)-primed $s g / s g$ (closed symbols) or $+1+$ (open symbols) spleen cells were added to a total of $5 \times 10^{6}$ spleen cells containing unprimed sg/sg (circles) or $+/+($ triangles) spleen cells. Proportions of primed and unprimed spleen cells are indicated on the abscissa. Cultures were immunized with SRBCTNP, and the anti-TNP PFC response was determined on day 4 from two cultures pooled for each point.

In this study we show that, in addition to the neurological malfunction, the $s g / s g$ mutation causes developmental and functional perturbations of the immune system. This dual effect of the $s g / s g$ mutation could suggest a developmental relationship between the nervous system and the immune system. Cerebellar cells and lymphocytes are known to share certain characteristics. For example, cerebellum and thymus develop approximately at the same time (embryonic day 10), the T-cell surface glycoprotein Thy-1 is expressed on neuronal cells (Williams and Gaguon, 1982), dopaminergic, cholinergic, and adrenergic innervation into the thymus has been described (Besedovsky and Sorkin, 1977; Bulloch and Pomerantz, 1984), and receptors for these neurotransmitters have been found on both brain cells and lymphocytes (Hall and Goldstein, 1981). An association of disturbed development of cerebellum and thymus has been described for the mouse mutation "wasted" (Schultz et al., 1982), for the athymic mouse $\mathrm{Nu} / \mathrm{Nu}$ (Henderson et al., 1981), and for the inherited human disease ataxia telangiectasia (Kaufman and Thiller, 1977; Peterson et al., 1964). The results reported here for $s g / s g$ provide an additional example of a developmental relationship between thymus and cerebellar cells through the combined effect of the $s g / s g$ mutation on both organs, phenotypically and functionally.

$\mathrm{Sg} / \mathrm{sg}$ spleen cells are capable of generating antibody-forming cells in vitro. However, they appear to be deficient in their ability to control or terminate the response. The in vitro $\mathrm{PFC}$ response was not only prolonged but, also, in the presence of primed helper T-cells, markedly increased (Table 2, Fig. 3). The in vitro $\mathrm{PFC}$ response of spleen cells is controlled by suppressor T-cells in a regulative feedback circuit (Cantor et al., 1978a, b), a mechanism deficient in NZB mice, which are prone to autoimmune disease (Cantor et al., 1978a). Our findings show delayed termination of the immune response and excessive response to the

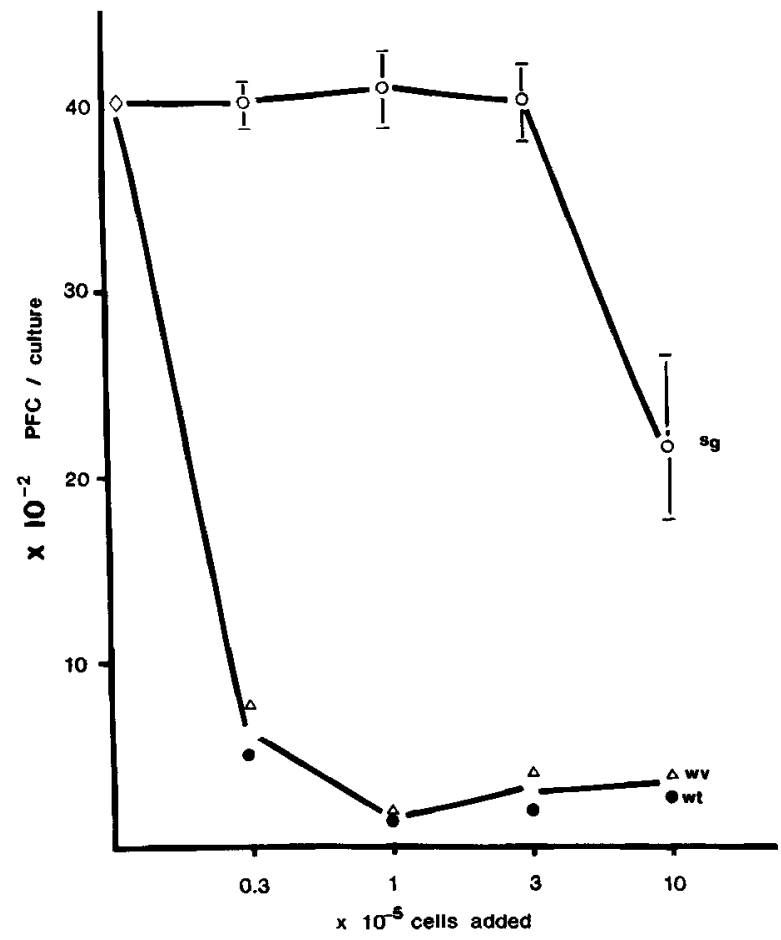

Figure 5. Failure of $\mathrm{sg} / \mathrm{sg}$ spleen cells to generate suppressor cells. Tcell suppression was determined in an allogenic system. $S g / s g, w v / w v$, or $+/+$ spleen cells $\left(\mathrm{H}-2^{b}\right)$ were titrated in the numbers indicated to cultures containing $5 \times 10^{6} \mathrm{Balb} / \mathrm{c} \mathrm{Nu} / \mathrm{Nu}$ spleen cells $\left(\mathrm{H}-2^{\mathrm{d}}\right)$. The cell mixtures were immunized with SRBC. A concanavalin A supernatant fraction (Hoffmann and Watson, 1979) was added at a final concentration of $10 \%$ as a source of IL-2 and TRF. Cultures also contained 30 $\mu / \mathrm{ml} \mathrm{IL-1} .+/+$ Spleen cells $(\Theta), s g / s g$ spleen cells $(0), w v / w v$ spleen cells $(\Delta)$, and control cultures with no cells added $(\diamond)$.

addition of activated helper T-cells, which might be adequately explained by a defective suppressor cell function in $\mathrm{sg} / \mathrm{sg}$. The inability of $s g / s g$ spleen cells to generate active suppressor cells when stimulated with alloantigen adds further support to this notion.

The neurological and immunological defects of $s g / s g$ mice cannot be attributed to the often-reduced physical condition of the animals and are unrelated to body weight or the size of spleen and thymus. In "weaver," another neurological mutation with distorted cerebellar development, the size of the thymus, the immune response, and cell-surface carbohydrate metabolism were normal even though homozygous weaver mice with a C57/BL background are generally in worse physical condition than $s g / s g$.

Gene product and its nature in the $s g / s g$ mutation are unclear. Our findings may place the link between neurological and immunological abnormalities on a developmental level, and one might speculate that the mutation disturbs the timing of differentiation processes, such as the expression of a developmental, stage-specific neuraminic acid. This would be consistent with the finding that the two organs affected by the mutation (cerebellum and thymus) develop simultaneously. It would furthermore provide a satisfactory explanation for the substantial variations seen in the severity of movement abnormalities and immune dysfunction. It is also relevant that cerebellum and thymus are innervated by the autonomic nervous system, and that the innervation pattern of the $s g / s g$ thymus has been reported to be abnormal (Bulloch and Loy, 1980; Bulloch and Pomerantz, 1984). Since the autonomic nervous system is said to modulate the function of innervated tissues via a neuroen- 
docrine axis (Besedovsky and Sorkin, 1977), the abnormal innervation may account for the immunological dysfunction.

The data presented above suggest that the autosomal recessive mutation $s g / s g$ affects both the nervous and the immune systems. We believe that this may lead to a consideration of inherited diseases in a new context. The $s g / s g$ mutation apparently does not affect only one cellular function, but, rather, causes a developmental deviation with consequences for more than one organ. Further analysis of cell-surface carbohydrate moieties, and in particular of cell-bound neuraminic acid, may shed further light on such developmental processes.

Note added in proof: It has recently come to our attention that in addition to previously recognized parallcls between the mouse mutant staggerer and the inherited human disease, ataxia-telangiectasia patients show a pronounced failure of allosuppression (Tasato and Blaese, 1985).

\section{References}

Aarden, L. A., et al. (1979) Revised nomenclature for antigen-non specific $T$ cell proliferation and helper factors. J. Immunol. 123: 2928 2929.

Besedovsky, H. O., and E. Sorkin (1977) Network of immune-neuroendocrine interaction. Clin. Exp. Immunol. 27: 1-12.

Bharanandan, V. P., A. K. Yeh, and R. Carubelli (1975) Neuraminidase assay utilizing sialyloligosaccharide substrates with tritium-labeled aglycone. Anal. Biochem. 69: 385-394.

Bulloch, K., and R. Loy (1980) The development of innervation in the thymus gland of wildtype and of the neuroimmune mutant staggerer. Soc. Neurosci. Abstr. 6: 69.

Bulloch, K., and W. Pomerantz (1984) Autonomic nervous system innervation of thymic-related lymphoid tissue in wildtype and nude mice. J. Comp. Neurol. 228: 57-68.

Cantor, H., L. McVay-Boudreau, J. Hugenberger, K. Naidorf, F. W. Shen, and R. F. Gershon (1978a) Immunoregulatory circuits among $T$ cell sets. II. Physiological role of feedback inhibition in vivo absence in NZB mice. J. Exp. Med. 147: 1116-1125.

Cantor, H., J. Hugenberger, L. McVay-Bondreau, D. D. Eardley, J. Kemp, F. W. Shen, and R. K. Gershon (1978b) Immunoregulatory circuits among $\mathrm{T}$-cell sets. I. Identification of a subpopulation of T helper cells that induce feedback inhibition. J. Exp. Med. 148: 871877.

Carubelli, R., and D. R. P. Tulsiani (1971) Neuraminidase activity in brain and liver of rats during development. Biochem. Biophys. Acta 237: 78-87.

Edelman, G. M., and C. M. Chuong (1982) Embryonic to adult conversion of neural cell adhesion molecules in normal and staggerer mice. Proc. Natl. Acad. Sci. USA 79: 7036-7040.

Finne, J., M. Leinonen, and P. H. Makela (1983) Antigenic similarities between brain components and bacteria causing meningitis. Lancet 2: 355-357.

Hall, N. R., and A. L. Goldstein (1981) Neurotransmitter and the immune system. In Psychoneuroimmunology, R. Ader, ed., pp. 521543, Academic, New York.

Hatten, M. E., and A. Messer (1978) Postnatal cerebellar cells from staggerer mutant mice express embryo cell surface characteristics. Nature 276: 504-505.

Henderson, R. S., B. McEwan, and E. M. Pantelouris (1981) Pituitary and cerebellum of nude mice. Thymus 3:359-368.

Hoffmann, M. K. (1980) Macrophages and T cells control distinct phases of B cell differentiation in the humoral immune response. J. Immunol. 125: 2076-2081.

Hoffmann, M. K., and J. W. Kappler (1973) Regulation of the immune response. II. Qualitative and quantitative differences between thymus and bone marrow derived lymphocytes. J. Exp. Med. 137: 721-739.

Hoffmann, M. K., and J. Watson (1979) Helper T cell replacing factor secreted by thymus-derived cells and by macrophages. J. Immunol. 122: 1371-1375.

Jerne, N. K., A. A. Nordin, and C. Henry (1963) Plaque formation in agar by a single antibody-producing cells. In Cell-Bound Antibodies (Conference of the National Academy of Sciences-National Research Council), p. 109, Wistar U. P., Philadelphia.

Kaufman, D. B., and H. G. Thiller (1977) Ataxia telangiectasia: An autoimmune disease associated with a cytotoxic antibody to brain and thymus. Clin. Immunol. Immunopathol. 7: 288-299.

Landis, D. M. D., and R. L. Sidman (1978) Electron microscopic analysis of postnatal histogenesis in the cerebellar cortex of staggerer mutant mice. J. Comp. Neurol. 179: 831-864.

Lefcovitz, I. (1972) Induction of antibody forming cell clones in microcultures. Eur. J. Immunol. 2: 360-366.

Liu, T. Y., E. C. Gotschlich, F. T. Dunne, and E. K. Jonssen (1971) Studies on the meningococeal polysaccharide II. Composition and chemical properties of the group $B$ and group $C$ polysaccharide. $J$. Biol. Chem. 246: 4703-4717.

Lowry, O. H., N. J. Rosebrough, A. L. Farr, and R. J. Randall (1951) Protein measurement with the folin phenol reagent. J. Biol. Chem. 193: 265-275.

Mishell, R. I., and R. W. Dutton (1967) Immunization of dissociated spleen cell cultures from normal mice. J. Exp. Med. 126: 423-442.

Peterson, R. O. A., W. D. Kelly, and R. A. Good (1964) Ataxia telangiectasia: Its association with a defective thymus immunological deficiency disease and malignancy. Lancet $1: 1189-1193$.

Roderick, T. H., and M. T. Davisson (1982) Linkage map of the mouse. In Handbook on Genetically Standardized Jaxmice, 3rd ed., p. 5.110, Bar Harbor, Maine.

Schultz, L. D., H. O. Sweet, M. T. Davisson, and D. R. Cowan (1982) 'Wasted,' a new mutant of the mouse with abnormalities characteristic of ataxia langiectasia. Nature 297: 402-404.

Sidman, R. L. (1968) Development of interneuronal connections in brains of mutant mice. In Physiological and Biochemical Aspects of Nervous Integration, F. D. Carlson, ed., pp. 163-193, Prentice-Hall, Englewood Cliffs, NJ.

Sidman, R. L., P. W. Lane, and M. N. Dickie (1962) Staggerer, a new mutation in the mouse affecting the cerebellum. Science 137: 610 612.

Tasato, G., and R. M. Blaese (1985) Defective allosuppression in patients with ataxia-telangiectasia. In Ataxia-Telangiectasia Genetics, Neuropathology, and Immunology of a Degenerative Disease of Childhood, pp. 331-338, Alan R. Liss, New York.

Trenkner, E. (1979) Postnatal cerebellar cells of staggerer mutant mice express immature components on their surfaces. Nature 277: 566568.

Trenkner, E., and S. Sarkar (1977) Microbial carbohydrate specific antibodies distinguish between different stages of differentiating mouse cerebellum. J. Supramol. Struct. 6: 465-472.

Wille, W., and E. Trenkner (1981) Changes in particulate neuraminidase activity during normal and staggerer mutant mouse development. J. Neurochem. 37: 443-446.

Williams, A. F., and J. Gaguon (1982) Neuronal cell Thy-1 glycoprotein: Homology with immunoglobulin. Science 216: 696-703. 